\title{
SISTEMA DE MONITORAMENTO E OTIMIZAÇÃO DO DESGASTE DOS TUBOS SUBMERSOS DE MÁQUINAS DE LINGOTAMENTO CONTÍNUO EM TEMPO REAL
}

\author{
Franz Ramstorfer ' \\ Charlie Denis Cordeiro Silva ${ }^{2}$ \\ Antonio Eli Nunes ${ }^{3}$ \\ Danilo Di Napoli Guzela ${ }^{4}$
}

\section{Resumo}

Este trabalho aborda o desenvolvimento de um sistema de monitoramento e de um algoritmo de otimização em tempo real do desgaste dos tubos submersos de máquinas de lingotamento contínuo. O sistema de monitoramento foi desenvolvido para informar, em tempo real, ao operador do molde sobre o estado do desgaste durante o lingotamento para evitar primeiramente o risco da utilização excessiva e consequente quebra do tubo. Este tipo de incidente implica sempre em um risco considerável para os operadores que trabalham removendo as partes quebradas no interior do molde, no sentido de evitar o risco de rompimento de veio devido a um aprisionamento de material não metálico junto à frente de solidificação. Os parâmetros do modelo matemático foram ajustados medindo-se o desgaste de uma série de exemplares de tubos utilizados pelo processo. Além disso, um algoritmo de otimização do desgaste foi desenvolvido para controlar a profundidade de imersão do tubo submerso. Com a implementação desses dois sistemas, não só o tempo de utilização dos tubos submersos pode ser melhorado, mas também, a segurança dos operadores e do processo.

Palavras-chave: Lingotamento contínuo; Tubos submersos; Monitoramento de desgaste em tempo real; Otimização de desgaste.

\section{REAL-TIME MONITORING AND WEAR OPTIMIZATION SYSTEM OF SUBMERGED ENTRY NOZZLES OF CONTINUOUS CASTING MACHINES}

\begin{abstract}
The present work is focused on the development of a real-time monitoring system and an optimization algorithm of the wear of submerged entry nozzles (SEN) of continuous slab casters. The real-time monitoring system was developed in order to inform the operator about the actual state of SEN wear during casting in order to avoid primarily the risk of an excessive use and a breakage of the SEN. This kind of incident always entails a considerable danger for the operators while removing the broken parts out of the mould and a risk of a breakout due to an entrapment of refractory parts in the strand too. The parameters of the mathematical model were adjusted by collecting process data and measuring the wear of various nozzles utilized at different casting conditions. Additionally, a wear optimization algorithm was developed for controlling the immersion depth of the SEN in order to maximize the usage time even it was already used at a constant immersion depth for some time. With the implementation of these two systems, not only the usage time of the submerged entry nozzles could be enhanced significantly, but also, at the same time, the operator and process safety.

Keywords: Continuous slab casting; Submerged entry nozzles; Real-time wear monitoring; Wear optimization.
\end{abstract}

\section{INTRODUÇÃO}

Durante o processo de lingotamento contínuo, o aço líquido tem que ser fornecido constantemente ao molde e protegido contra a oxidação. Os tubos submersos, feitos de material refratário numa base de alumina-grafite $\left(\mathrm{Al}_{2} \mathrm{O}_{3}-\mathrm{C}\right)$, são utilizados para atender a essas necessidades.
O pó fluxante é espalhado sobre o aço líquido no molde para protegê-lo da oxidação, lubrificar o veio sólido no molde e prender as inclusões não metálicas. Além das suas funções principais, o pó fluxante causa uma erosão externa do tubo submerso na zona de contacto no menisco. Nesta

'Engenheiro Mecânico Ph.D., Especialista de processos, Usiminas, Cubatão, SP, Brasil. E-mail: franz.ramstorfer@usiminas.com

${ }^{2}$ Engenheiro Eletricista, Engenheiro de manutenção, Usiminas, Cubatão, SP, Brasil.

${ }^{3}$ Engenheiro Metalurgista, Gerente de lingotamento, Usiminas, Cubatão, SP, Brasil.

${ }^{4}$ Engenheiro Metalurgista, Gerente de processos de aciaria, Usiminas, Cubatão, SP, Brasil. 
região, onde o tubo submerso está em contato com o pó fluxante líquido, o corpo do tubo submerso é protegido adicionalmente com uma camada protetora de zircônia-grafite, $\left(\mathrm{ZrO}_{2}-\mathrm{C}\right)$ devido à sua elevada resistência contra a corrosão. A Figura I mostra uma seção longitudinal de um tubo submerso depois do uso em três profundidades de imersão i.e. $135 \mathrm{~mm}, 155 \mathrm{~mm}$ e $175 \mathrm{~mm}$.

Os modelos do ataque do tubo submerso, que foram propostos, são baseados em forma de mecanismo de dissolução cíclico dos componentes refratários principais, zircônia e grafite [1,2]. Como um resultado, o processo de corrosão depende principalmente do tipo de pó fluxante $[3,4]$, do teor de carbono do aço lingotado $[1,5]$ e das características do material refratário $[1,3]$. Em particular, um pó fluxante com uma menor viscosidade e um maior teor de flúor, provoca um desgaste mais rápido do material refratário. Os estudos também mostram que os aços de baixo teor de carbono promovem um maior desgaste do refratário devido a uma dissolução maior do grafite. Também um teor de zircônia mais alto da camada protetora induz uma taxa de erosão menor.

Em caso de uso excessivo do tubo submerso, ele pode ser furado ou pode quebrar devido à falta de monitoramento e o controle do desgaste. Em caso de quebra do tubo submerso, os operadores têm que "pescar" as peças quebradas, a qual é uma atividade perigosa. Se permanecerem os restos do tubo submerso dentro do molde, pode causar um rompimento de pele do aço que ainda não solidificou completamente, com consequências imprevisíveis de segurança operacional e perda na produção. O objetivo é otimizar o tempo de uso do tubo submerso (redução de custos) e no mesmo tempo a segurança dos operadores e do processo tem que ser garantida também. Um modelo matemático do desgaste do tubo submerso foi apresen-

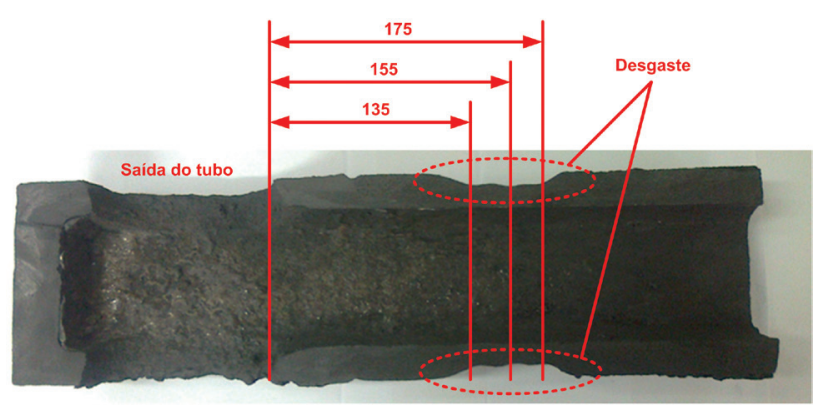

Figura I. Seção longitudinal de um tubo submerso depois do uso em três profundidades de imersão. tado em trabalhos [6,7] anteriores buscando otimizar o desgaste do tubo, como uma ferramenta de simulação tipo off-line. Ou seja, a ferramenta de simulação só foi utilizada para desenvolver estratégias de uso dos tubos submersos, que não resultam em uma ajuda ao operador durante o processo de lingotamento real, porque o controle do desgaste fica ainda na responsabilidade dos operadores, através de um controle do tempo de operação e profundidade do tubo submerso.

O objetivo do presente trabalho é o desenvolvimento de um sistema de monitoramento do desgaste do tubo submerso, em tempo real, utilizando um modelo matemático do desgaste e o desenvolvimento de um algoritmo de otimização baseado do desgaste calculado em tempo real.

\section{METODOLOGIA}

O primeiro passo do desenvolvimento foi a caracterização do desgaste através de medições do desgaste de vários tubos submersos utilizados em condições de uso diferentes. Neste trabalho, o resultado da caracterização de quatro tubos utilizados na máquina de lingotamento 3 em Cubatão é mostrado. Estes tubos com um corpo de alumina-grafite e uma camada protetora de zircônia-grafite (84\% teor de zircônia) na região de contato com o pó fluxante líquido foram analisados. As composições químicas desejadas do tipo de aço de médio carbono e do pó fluxante são mostradas nas Tabelas I e 2.

Além da composição química, o pó fluxante é caracterizada por uma basicidade $\left(\mathrm{CaO} / \mathrm{SiO}_{2}\right)=1.3$ e uma viscosidade na temperatura de $1.300^{\circ} \mathrm{C}=0.7 \mathrm{Pas}$.

Para caracterizar o desgaste real, vários tubos usados foram cortados (Figura I) e os perfis de desgaste foram medidos manualmente. Nas Figuras 2 e 3, os perfis de desgaste diferentes são mostrados. Na Figura 3, a camada protetora é mostrada em amarelo. A Figura 4 mostra a profundidade de imersão, durante a utilização de cada tubo.

As Figuras 3 e 4 mostram também que o Tubo \# I foi utilizado excessivamente numa profundidade de imersão de $145 \mathrm{~mm}$. $O$ desgaste observado nesta posição já ultrapassou a camada de zircônia. A seguir, estes dados de medição são utilizados para elaborar um modelo matemático do desgaste.

Tabela I. Composição química do aço lingotado

\begin{tabular}{cccccccc}
\hline Elemento & $\mathbf{C}$ & $\mathbf{M n}$ & $\mathbf{S i}$ & $\mathbf{P}$ & $\mathbf{S}$ & $\mathbf{A l}$ & $\mathbf{T i}$ \\
\hline Teor [\%] & 0,160 & $\mathrm{I}, 100$ & 0,270 & 0,022 & 0,008 & 0,030 & 0,035 \\
\hline
\end{tabular}

Tabela 2. Composição química do pó fluxante

\begin{tabular}{ccccccccc}
\hline Elemento & $\mathbf{S i O}_{2}$ & $\mathbf{C a O}$ & $\mathbf{M g O}$ & $\mathbf{A l}_{2} \mathbf{O}_{3}$ & $\mathbf{N a}_{2} \mathbf{O}$ & $\mathbf{F}$ & $\mathbf{C l i v}$ & $\mathbf{C O}_{2}$ \\
\hline Teor $[\%]$ & 30,3 & 39,4 & 2,3 & 3,3 & 7,8 & 7,7 & 3,0 & 5,6 \\
\hline
\end{tabular}




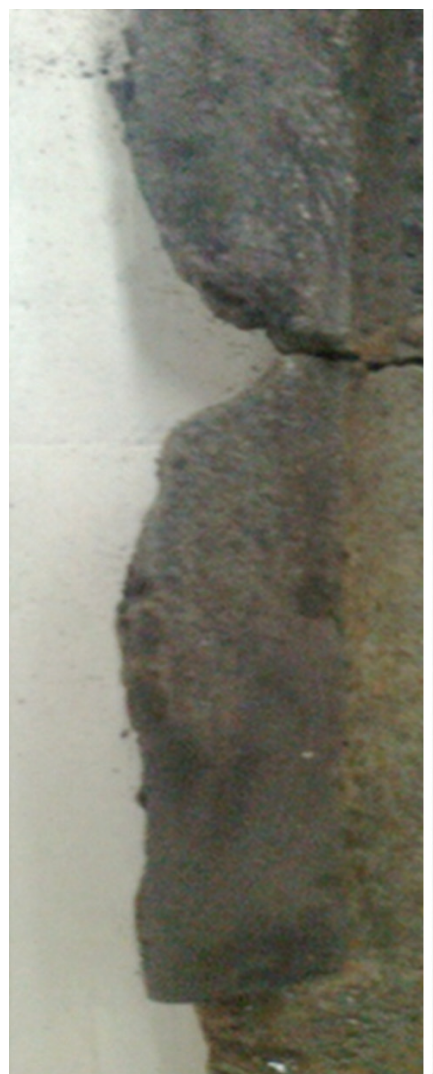

Tubo \#1

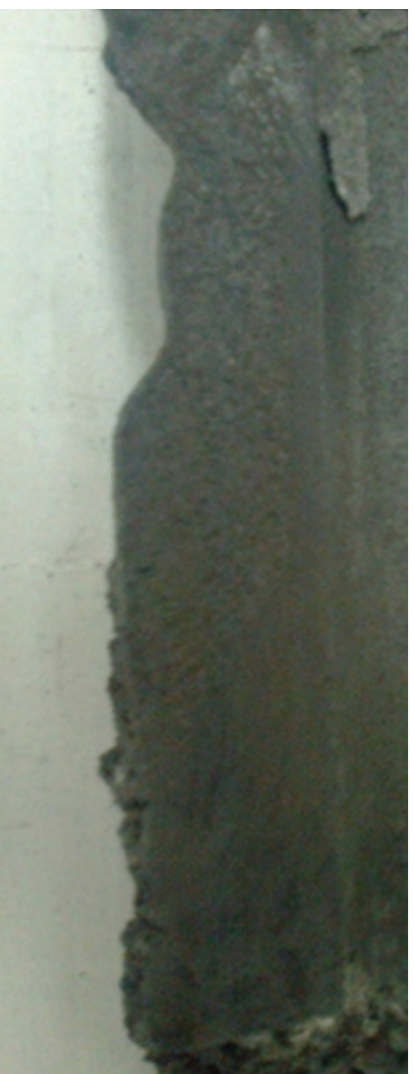

Tubo \#2

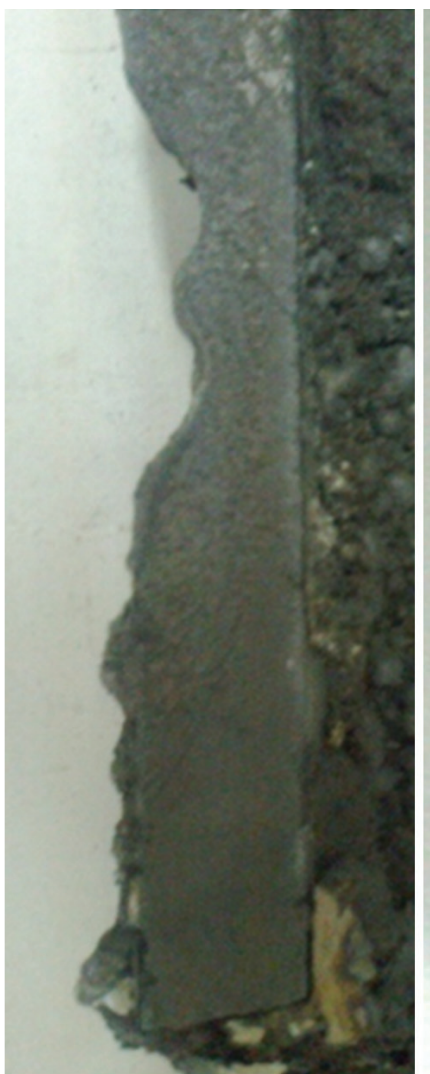

Tubo \#3

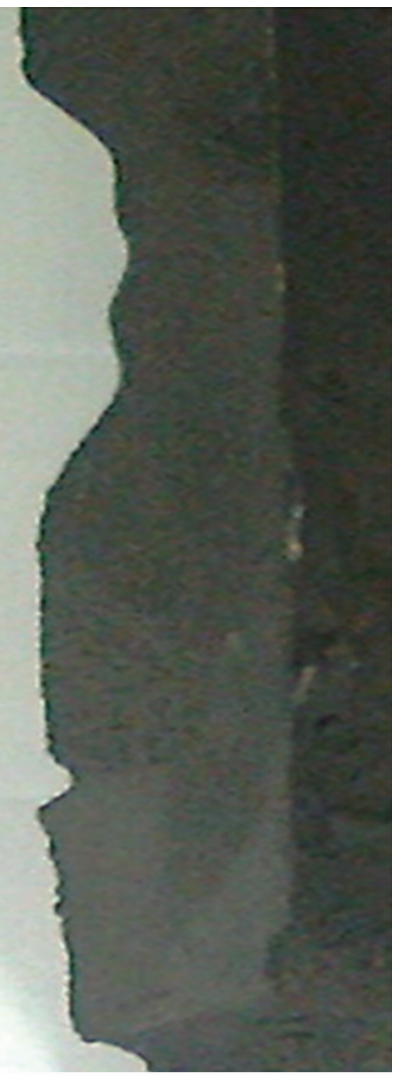

Tubo \#4

Figura 2. Regiões de desgaste dos quatro tubos submersos analisados.

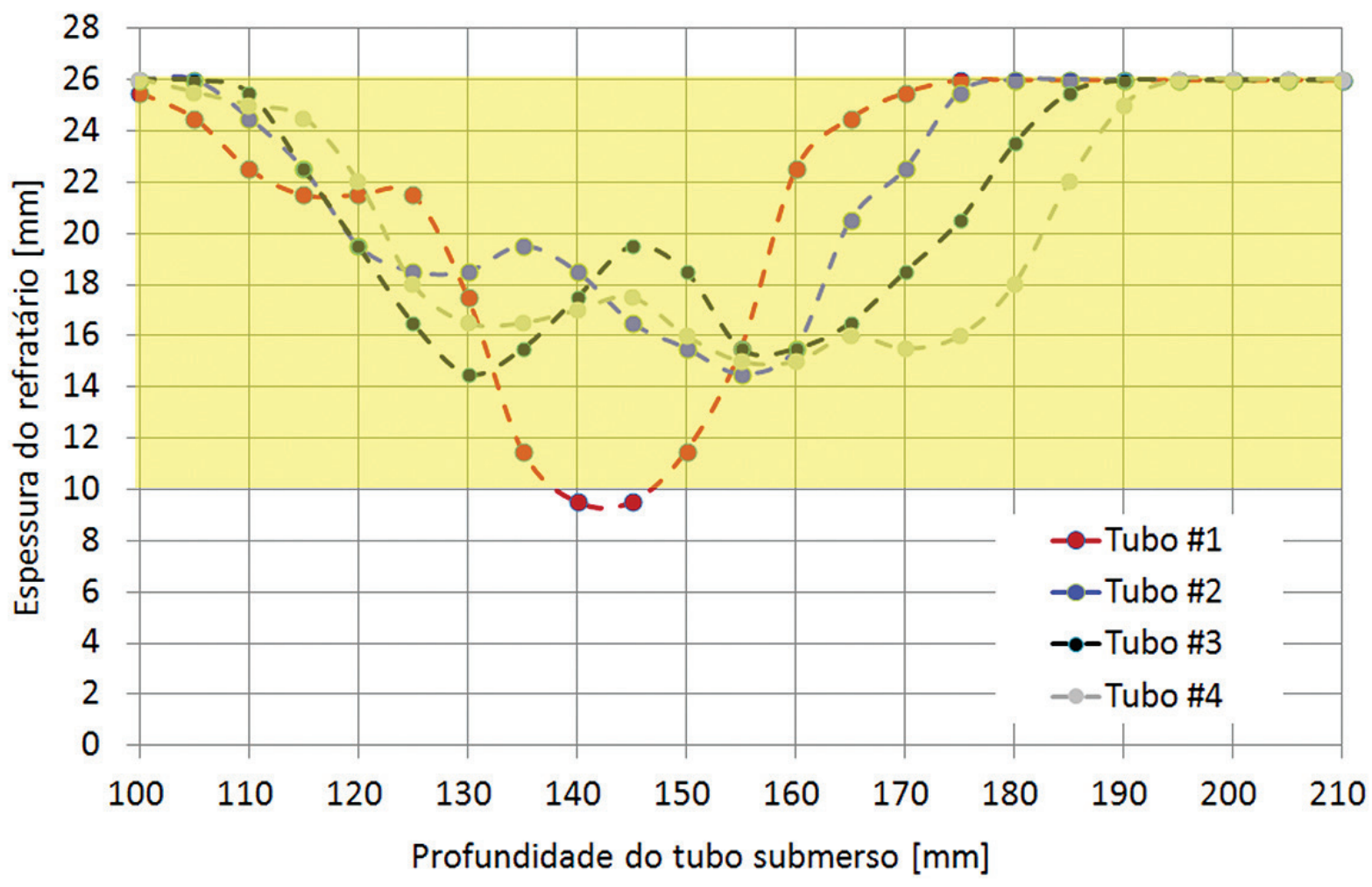

Figura 3. Resultados das medições do desgaste dos quatro tubos submersos. 


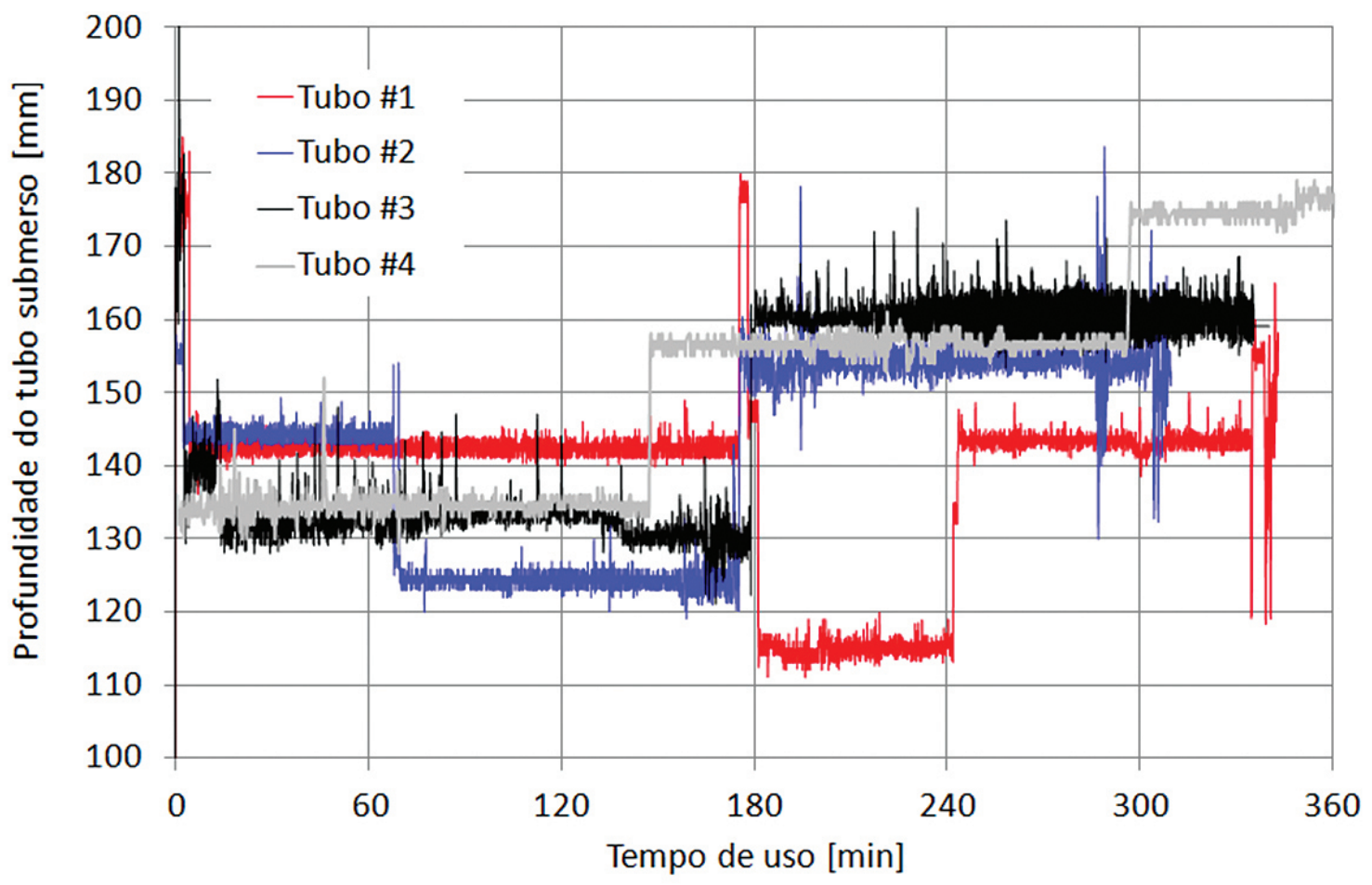

Figura 4. Profundidade de imersão durante a utilização dos quatro tubos submersos.

Conforme os trabalhos [6,7], o desgaste do tubo submerso é afetado primariamente pela profundidade do tubo submerso. De acordo com esses autores, o desgaste encontrado neste trabalho foi modelado utilizando a seguinte função tipo Gauss:

$$
E(x, t)=E_{0}-V_{D} \cdot t \cdot \exp \left(-\frac{\left(P_{T S}-x\right)^{2}}{P_{3}}\right)
$$

Onde $E(x, t)$ significa a espessura do refratário, $E 0$ é a espessura inicial antes do uso, $x$ a posição no tubo submerso, VD a taxa de erosão linear, PTS a profundidade do tubo submerso e $t \circ$ tempo de contato entre $\circ$ pó fluxante líquido e o material refratário na posição $x$. A largura do perfil de ataque, conforme Figura 5 , é descrita pelo fator P3. A raiz quadrada do fator P3 representa a distância entre o valor máximo da erosão, na profundidade de imersão atual PTS e o ponto de inflexão da função tipo Gauss (Figura 5).

Enquanto as variáveis E0 e PTS são conhecidas, os parâmetros de desgaste do modelo VD e P3 têm que ser ajustados através dos dados de medição.

Para calcular $\circ$ desgaste numericamente, a equação analítica (I) foi transformada para uma equação discreta:

$$
E\left(x_{i}, t+\Delta t\right)=E\left(x_{i}, t\right)-V_{D} \cdot \exp \left(-\frac{\left(P_{T S}-x_{i}\right)^{2}}{P_{3}}\right) \cdot \Delta t
$$

Equação 2 foi implementada em um programa computacional para resimular o desgaste dos Tubos \# I

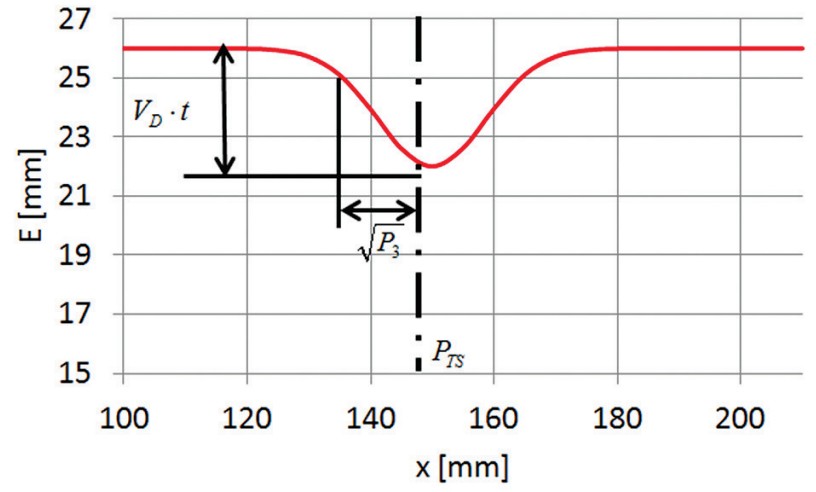

Figura 5. Função do desgaste tipo Gauss.

a \#4 através dos quatros históricos de profundidade de imersão reais e ajustar assim os parâmetros não conhecidos, VD e P3. Os valores dos parâmetros VD $=4 \mathrm{~mm} / \mathrm{h}$ e P3 $=150 \mathrm{~mm}^{2}$ deram a melhor concordância entre os perfis de desgaste medidos e os resultados das simulações. A comparação entre as previsões do modelo e as medições é mostrada na próxima Figura 6.

\section{RESULTADOS}

A informação da profundidade de imersão do tubo submerso PTS é enviada, em tempo real, pelo sistema de Nível I - CLP (Controlador Lógico Programável) para o modelo e assim o desgaste é calculado em tempo real e é visível aos operadores. Com essa informação on-line, os 
operadores sempre sabem o estado atual do desgaste e podem ajustar a profundidade de imersão, caso a camada de proteção atinja a espessura mínima numa posição. Opcionalmente, eles podem decidir trocar $\circ$ tubo submerso, se a camada de proteção estiver completamente desgastada. A tela do sistema de monitoramento implementado na máquina de lingotamento 3 em Cubatão é mostrada na Figura 7.

Além do desgaste calculado do tubo submerso (diagrama à direita), o sistema informa ao operador sobre o histórico da profundidade de imersão (diagrama à esquerda). $O$ tempo desde o início do uso, o tempo

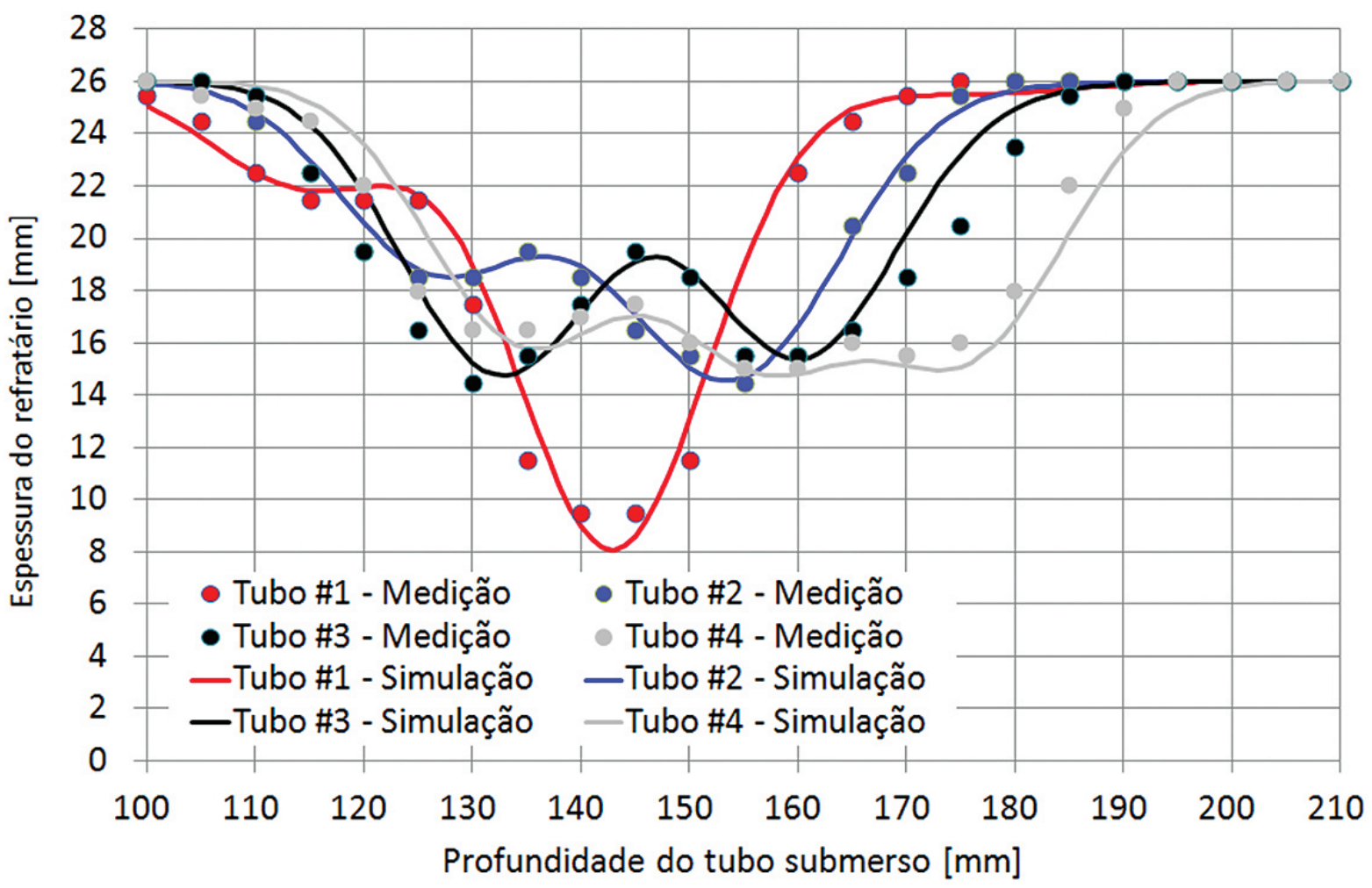

Figura 6. Comparação das medições (pontos) contra as previsões do modelo (linhas). Uma condição muito boa foi atingida usando os parâmetros de modelo VD $=4 \mathrm{~mm} / \mathrm{h}$ e P3 $=150 \mathrm{~mm} 2$.

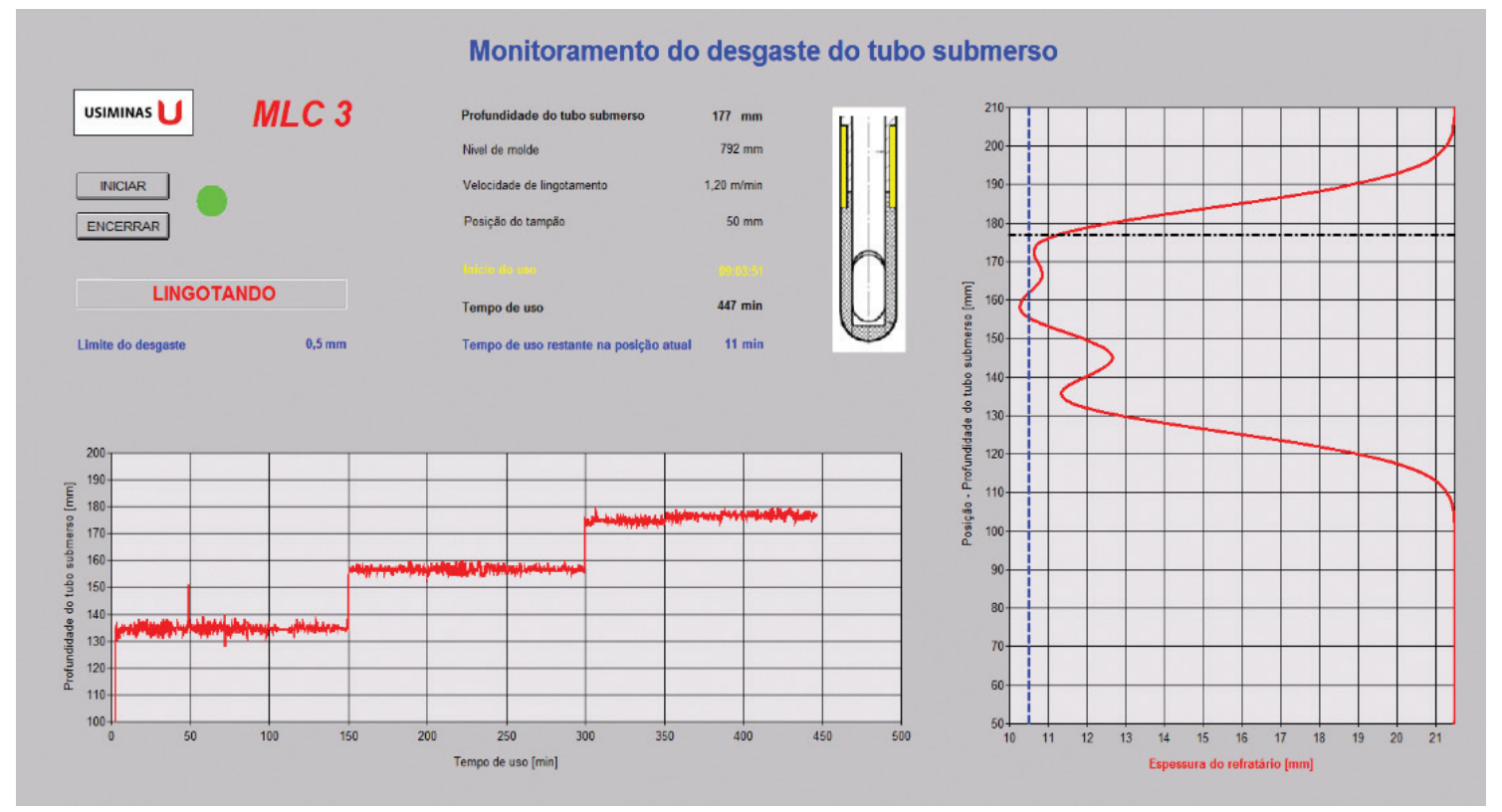

Figura 7. Sistema de monitoramento do desgaste do tubo submerso implementado na máquina de lingotamento 3 em Cubatão. 
de uso restante no qual o tubo submerso ainda pode ser utilizado até a espessura mínima da camada protetora de zircônia ser atingida na profundidade de imersão atual. Adicionalmente, não há necessidade de qualquer interação dos operadores, pois o sistema reinicializa o cálculo do desgaste automaticamente, depois de uma troca do tubo submerso.

O sistema de monitoramento on-line do desgaste representa apenas um sistema passivo. $O$ operador ajusta a profundidade de imersão do tubo submerso e pode ver $\circ$ resultado deste ajuste. Este sistema de monitoramento do desgaste, em tempo real proporciona a base de uma otimização do desgaste em tempo real baseado no cálculo deste sistema de monitoramento on-line. Com isso, é possível usar a informação do desgaste, em tempo real, para controlar automaticamente a profundidade de imersão do tubo submerso a fim de otimizar o desgaste sem a interação do operador.
Um algoritmo, que usa a informação do desgaste do tubo atual, foi elaborado para otimizar o desgaste em tempo real. As cinco subetapas principais deste algoritmo são:

- Na subetapa I, o cálculo do desgaste é inicializado (desgaste e tempo de uso iguais á zero) automaticamente quando um novo tubo submerso é montado na máquina de lingotamento;

- Na subetapa 2, o modelo de desgaste é alimentado (atualizado) continuamente em intervalos de tempo fixos, pela profundidade de imersão real. A profundidade de imersão é calculada utilizando a informação dos sensores de posição dos cilindros de ajuste de altura do distribuidor e o sinal do nível do aço no molde. Nessa subetapa, se for considerado que o desgaste está no limite, o tubo submerso deve ser trocado. Com a montagem de um novo tubo, o processo é reiniciado a partir da subetapa I;
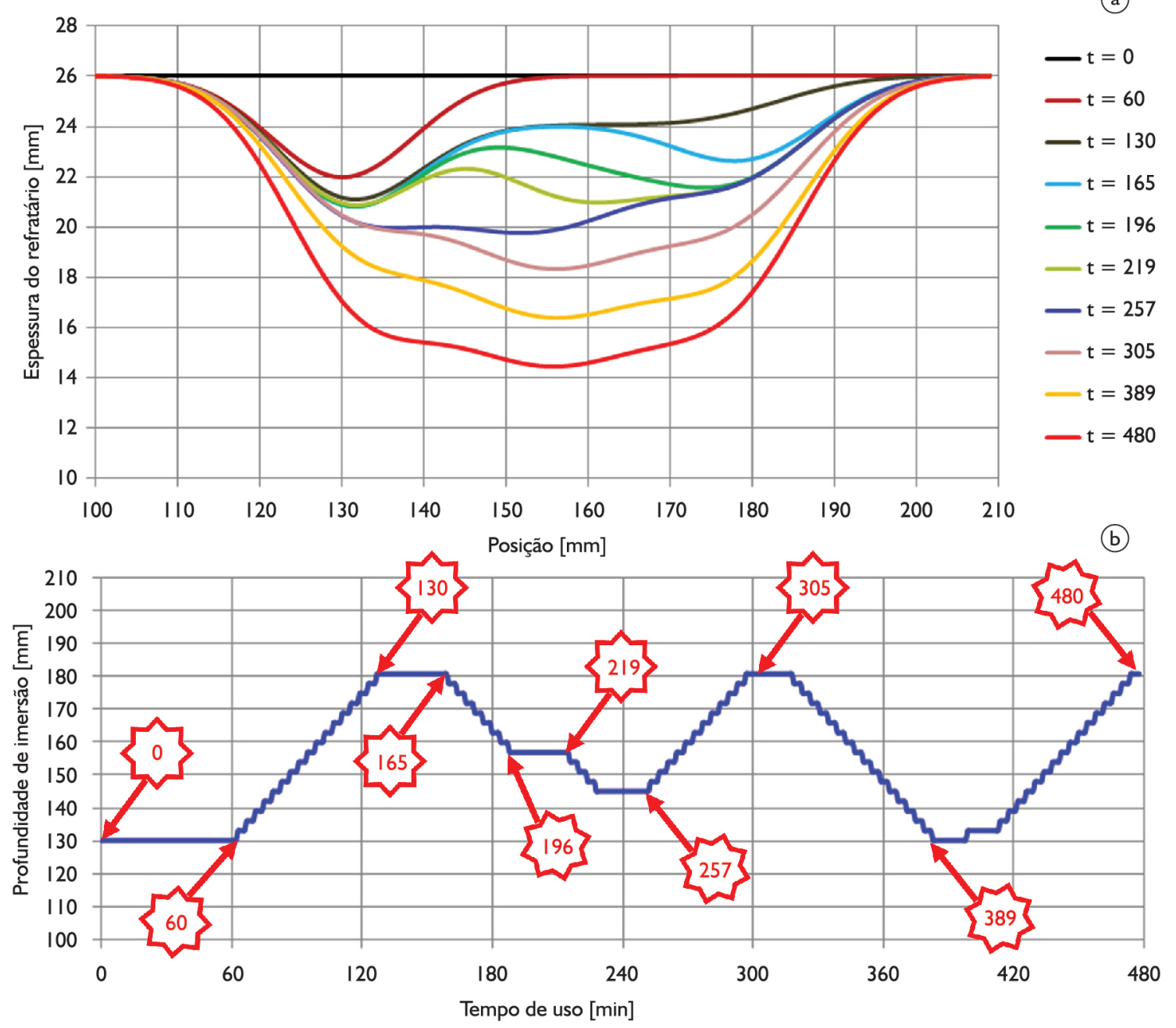

Figura 8. Funcionamento do algoritmo mostrado através de várias etapas de simulação. Perfil de desgaste (a) e profundidade de imersão (b) em vários pontos de tempo de uso. 
- Na subetapa 3, o algoritmo procura a profundidade de imersão da maior espessura da camada protetora calculada em tempo real entre o valor máximo e mínimo, (faixa de operação) da profundidade de imersão (por exemplo: entre $130 \mathrm{~mm}$ e $170 \mathrm{~mm}$ );

- A mudança da profundidade de imersão atual à profundidade nova, determinada na subetapa 3 , é feita gradativamente $(2-10 \mathrm{~mm}$ a cada I - 5 min.) na subetapa 4 , através de comandos fornecidos do CLP para as válvulas hidráulicas que atuam nos cilindros do distribuidor (mudança da posição física do distribuidor) ou pelo ajuste do nível do molde pelo controlador do nível do aço no molde;

- Na última subetapa 5 , depois do movimento gradativo para a profundidade de imersão nova, esta profundidade de imersão é mantida por um tempo determinado. Este tempo é calculado utilizando o valor recíproco da espessura da camada protetora do tubo submerso nesta posição. Depois deste tempo, o algoritmo volta para a subetapa 3.

O funcionamento prático do algoritmo é mostrado, passo a passo na Figura 8, através de um exemplo de simulação.

Depois de iniciar a simulação, a profundidade de imersão de $130 \mathrm{~mm}$ foi mantida constante por 60 minutos. Após este uso em modo manual, o algoritmo de otimização foi ligado, e procedeu conforme as etapas definidas anteriormente. A simulação foi interrompida com $480 \mathrm{~min}$, mostrando afinal um perfil de desgaste homogêneo, sem influência obvia do uso em modo manual.

Como resultado, o desgaste do tubo submerso é sempre otimizado, mesmo que o operador tenha usado o tubo submerso no modo manual durante algum tempo. O tempo do uso total também não depende mais da profundidade inicial. Este sistema pode ser implementado em qualquer máquina de lingotamento que fornece um sinal da profundidade do tubo submerso em tempo real e possui ajuste da profundidade de imersão do tubo submerso pelo PLC. Conforme o exemplo de (a)

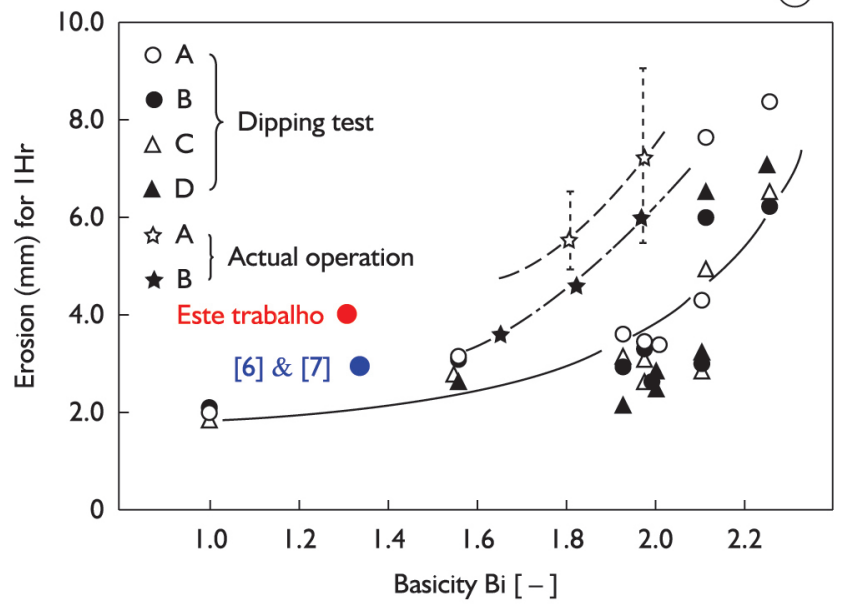

(c)

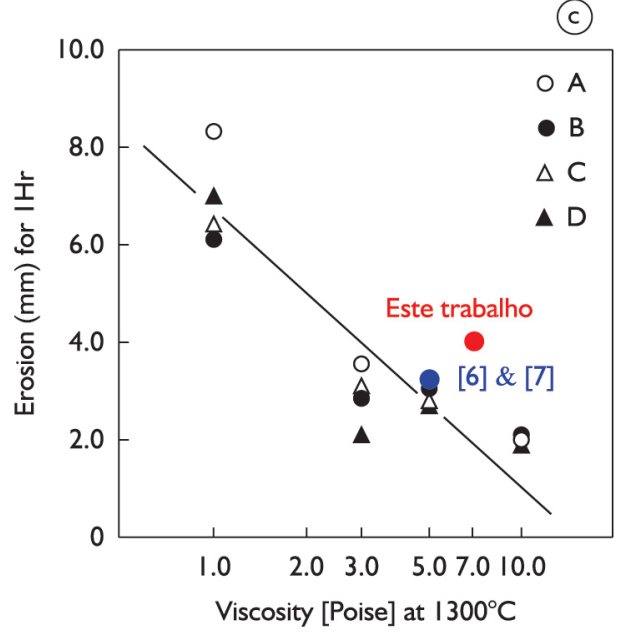

(b)

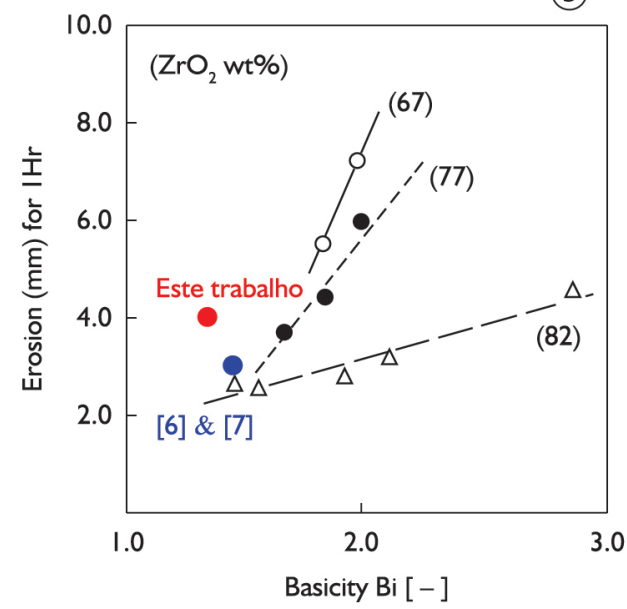

(d)

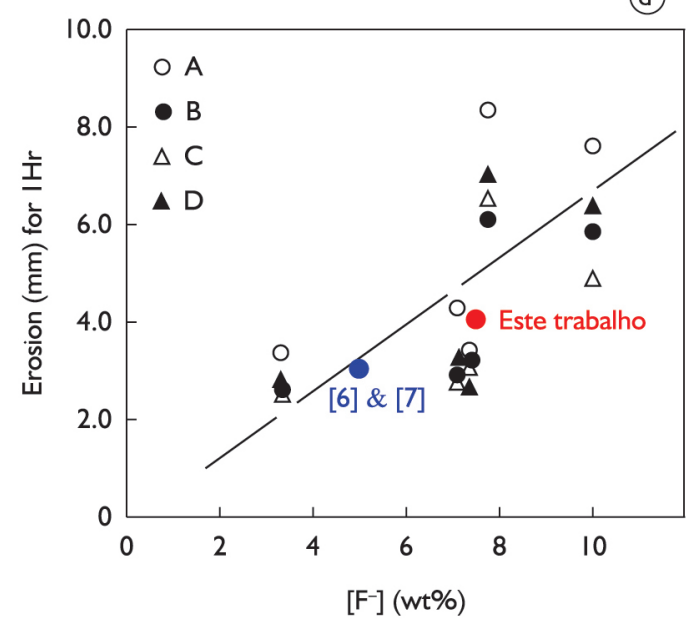

Figura 9. A comparação da taxa de erosão do VD deste trabalho com os valores na literatura $[3,6,7]$. Taxa de erosão VD em função da basicidade (a) e (b), viscosidade (c), teor de flúor (d) do pó fluxante e do teor de zircônia da camada protetora (b). 
simulação na Figura 8, o tempo de uso total de 8 horas, considerando uma faixa de operação da profundidade do tubo submerso entre $130 \mathrm{~mm}$ e $180 \mathrm{~mm}$. A comparação deste resultado, com a prática de operação atual, utilização o tubo em duas linhas de desgaste de 3 horas, mostra que o tempo de utilização total pode ser aumentado até $30 \%$.

\section{DISCUSSÃO}

A base da precisão do sistema de monitoramento on-line do desgaste e o otimizador de desgaste em tempo real são os parâmetros do modelo (a taxa linear de corrosão VD e o parâmetro de largura da corrosão P3). Neste trabalho são mostrados apenas os resultados de uma configuração dos vários testes feitos. Para oferecer uma visão mais ampla, a taxa de corrosão linear obtida de $4 \mathrm{~mm} / \mathrm{h}$ é comparada com os resultados disponíveis na literatura $[3,6,7]$. A Figura 9 mostra que embora o pó fluxante utilizado tenha basicidade menor e uma viscosidade maior em comparação aos encontrados em outros trabalhos [6,7], a taxa de erosão obtida nas medições atuais é maior.

Dessa forma, de acordo com os diagramas das Figuras $9 a, 9 b$ e $9 c$, os resultados não correspondem a um comportamento do desgaste mostrado na literatura $[3,6,7]$, mas há uma correspondência, muito boa, da taxa de erosão com o conteúdo de flúor do pó fluxante, mostrado na Figuras 9d.

\section{CONCLUSÃo}

No presente trabalho, o desgaste de vários tubos submersos foi analisado através da medição do perfil de desgaste deles. Os resultados das medições foram utilizados para ajustar os parâmetros de um modelo matemático do desgaste. Este modelo foi implementado num sistema de monitoramento online, para informar aos operadores em tempo real, sobre o estado atual do desgaste do tubo submerso. É possível também usar esta informação do desgaste em tempo real para otimizar o desgaste do tubo submerso, através de um algoritmo sem intervenção do operador, mesmo que o operador tenho usado o tubo submerso no modo manual durante algum tempo. Com a aplicação deste desenvolvimento apresentado, testes preliminares mostraram que, o tempo de uso dos tubos submersos pode ser aumentado até $30 \%$ e, no mesmo tempo, quebras dos tubos submersos, com todas as consequências da segurança não desejadas, podem ser reduzidas para o mínimo possível.

\section{REFERÊNCIAS}

I Mukai K, Toguri JM, Stubina NM, Yoshitomi J. A mechanism for the local corrosion of immersion nozzles. Journal of the Iron and Steel Institute of Japan. 1989;29(6):469-476. http://dx.doi.org/ 10.2355/isijinternational.29.469

2 Dick AF, Yu X, Pomfret RJ, Coley KS. Attack of submerged entry nozzles by mould flux and dissolution of refractory oxides in the flux. Journal of the Iron and Steel Institute of Japan. 1997;37(2): I02- I08. http://dx.doi.org/ I0.2355/ isijinternational.37.102

3 Nakamura Y, Ando T, Kurata K, Ikeda M. Effect of chemical composition of mold powder on the erosion of submerged nozzles for continuous casting of steel. Transactions of the Iron and Steel Institute of Japan. | 986;26(I 2): I 052- I058. http://dx.doi.org// 0.2355/isijinternational I 966.26. 1052

4 Bruce DW, Hunter NS. Utilization of mould thermal monitoring for improvement of bloom surface quality on the british steel, teesside works 8-strand bloom caster. In: German Iron and Steel Institute. Proceedings of the 2nd European Continuous Casting Conference; 1994 June 20-22; Düsseldorf, Alemanha. Düsseldorf: VDEh; I994. p. $|56-| 6 \mid$.

5 Höffken E, Lax H, Pietzko G. Development of improved immersion nozzles for continuous slab casting. In: Centre de Recherches Métallurgiques, German Iron and Steel Institute. Proceedings of the 4th International Conference on Continuous Casting; 1988 May 17-19; Bruxelas, Bélgica. Bruxelas: Stahl Eisen; 1988. v. 2, p. 46I-473.

6 Capurro C, Cicutti C, Galliano P, Fuhr F, Torga G, Walter G. Characterization of wear of submerged entry nozzles used in the continuous casting of steel. In: Instituto Argentino de Siderurgia. Proceedings of the I5th Steelmaking Conference; 2005 November 8-10; San Nicolas, Argentina. San Nicolas: IAS; 2005. p. 59I-60I.

7 Capurro C, Cicutti C, Galliano P, Fuhr F, Torga G, Scoccia J. Optimization of submerged entry nozzles wearing. In: Associazione Italiana di Metallurgia. Proceedings of the 6th European Conference on Continuous Casting; 2008 June 3-6; Riccione, Itália. Riccione: AIM; 2008. p. 384-394.

Recebido em: 18 Set. 2013

Aceito em: 12 Maio 2014 